\title{
Salary and Quality Compensation for Physician Practices Participating in Accountable Care Organizations
}

\author{
Andrew M. Ryan, PbD \\ Stephen M. Shortell, PbD, MPH, \\ $M B A^{2}$
}

Patricia P. Ramsay, MPH ${ }^{2}$

Lawrence P. Casalino, $M D, P b D^{3}$

'Department of Health Management and Policy, School of Public Health, University of Michigan, Ann Arbor, Michigan

${ }^{2}$ Division of Health Policy and Management, School of Public Health, University of California Berkeley, Berkeley, California

${ }^{3}$ Division of Healthcare Policy and Economics, Department of Health Policy and Economics, Weill Cornell Medical College, New York, New York

\section{बhin \\ MORE ONLINE \\ www.annfammed.org}

Conflicts of interest: authors report none.

\section{CORRESPONDING AUTHOR}

Andrew M. Ryan, PhD

School of Public Health, University of Michigan

Department of Health Management and Policy

1415 Washington Heights

Ann Arbor, MI 48109

amryan@umich.edu

\begin{abstract}
BACKGROUND The accountable care organization (ACO) is a new organizational form to manage patients across the continuum of care. There are numerous questions about how ACOs should be optimally structured, including compensation arrangements with primary care physicians.
\end{abstract}

METHODS Using data from a national survey of physician practices, we compared primary care physicians' compensation between practices in ACOs and practices that varied in their financial risk for primary care costs using 3 groups: practices not participating in a Medicare ACO and with no substantial risk for primary care costs; practices not participating in an ACO but with substantial risk for primary care costs; and practices participating in an ACO regardless of their risk for primary care costs. We measured physicians' compensation as the percentage of compensation based on salary, productivity, clinical quality or patient experience, and other factors. Regression models estimated physician compensation as a function of ACO participation and risk for primary care costs while controlling for other practice characteristics.

RESULTS Physicians in ACO and non-ACO practices with no substantial risk for costs on average received nearly one-half of their compensation from salary, slightly less from productivity, and about $5 \%$ from quality and other factors. Physicians not in ACOs but with substantial risk for primary care costs received two-thirds of their compensation from salary, nearly one-third from productivity, and slightly more than $1 \%$ from quality and other factors. Participation in ACOs was associated with significantly higher physician compensation for quality; however, participation was not significantly associated with compensation from salary, whereas financial risk was associated with much greater compensation from salary.

CONCLUSION Although practices in ACOs provide higher compensation for quality, compared with practices at large, they provide a similar mix of compensation based on productivity and salary. Incentives for ACOs may not be sufficiently strong to encourage practices to change physician compensation policies for better patient experience, improved population health, and lower per capita costs.

Ann Fam Med 2015;13:321-324. doi: 10.1370/afm.1805.

\section{INTRODUCTION}

7 he accountable care organization (ACO) programs created by the US Patient Protection and Affordable Care Act are dramatic departures for care delivery and payment in Medicare. In Medicare's ACO programs, provider organizations-including physician practices, hospitals, and post-acute care facilities-agree to be responsible for the cost and quality outcomes of a population of Medicare beneficiaries. Beneficiaries are attributed to ACOs on the basis of their use of primary care services. To avoid higher cost specialty and acute care, primary care physicians must coordinate care efficiently.

There are numerous questions about how ACOs should be structured to achieve their goals. ${ }^{1}$ One question concerns compensation arrangements: how should practices in ACOs pay primary care physicians to 
create incentives for meeting quality measures while constraining costs? The ACO payment model provides incentives for efficiency that are on the continuum between no-risk, fee-for-service payment and full-risk, capitated payment. ${ }^{1,2}$ If ACOs bore financial risk only for primary care costs, salaried compensation would align the interests of physicians and ACOs to decrease primary care costs. ACOs are at risk, however, for the total cost of care, not just primary care costs. Salaried compensation may increase the propensity of physicians to refer difficult or time-consuming patients to specialists, ${ }^{3}$ thereby increasing costs. Productivity compensation for primary care physicians_-based on the volume of billed services-may alleviate this problem by encouraging physicians to expand their scope of practice. ${ }^{4}$ Productivity compensation, however, may also encourage primary care physicians to rush through visits to see more patients and bill at higher evaluation and management codes, also increasing costs. It is also unclear whether practices in ACOs should link primary care physicians' compensation to measures of quality.

Because of data limitations, research that has examined the interaction between practice payment incentives and physicians' compensation has been limited. ${ }^{5,6}$ None of this research has been conducted in the context of ACOs. In this article, we examined whether practices in ACOs pay their primary care physicians as they do any other practice or use compensation policies that are similar to practices that assume substantial risk for primary care costs.

\section{METHODS}

We used data from the third National Survey of Physician Organizations (NSPO3). NSPO3 is a nationally representative survey of physician practices in the United States and was administered to practice leaders between January 2012 and November 2013 (1,398 responses for a response rate of $49.7 \%$ ). After excluding solo practitioners, practices for which at least $33 \%$ of physicians were not primary care, and practices with missing data, our analytic sample comprised 632 practices. Solo practitioners were excluded because they were not eligible to answer the survey question about the makeup of their compensation (see below). The survey instrument has been described in detail elsewhere. ${ }^{1}$

We measured compensation as the percentage of primary care physician compensation that was based on salary, productivity, clinical quality or patient experience, and other factors. Practices were classified as having substantial risk for primary care costs if they had some financial risk for all their health maintenance organization and point-of-service patients. This risk may be through ACO contracts or through other contracts with Medicare or commercial insurers. Given the low levels of financial risk for specialty costs in our sample $(81.1 \%$ of practices had no risk for specialty costs) - particularly for primary care practices $(90.7 \%$ of which had no risk for specialty costs)—we did not consider specialist risk or specialist compensation in our analysis.

We compared primary care compensation between 3 mutually exclusive groups: practices that were not participating in a Medicare ACO and did not have substantial risk for primary care costs $(76.1 \%$ of practices) ${ }_{i}$ practices that were not participating in an ACO but did have substantial risk for primary care costs ( $2.8 \%$ of practices $)_{i}$ and practices that were participating in an ACO regardless of their risk for primary care costs (21.1\% of practices). Although practices that were not participating in an ACO but had substantial risk for primary care costs made up a small percentage of the sample, this group was important because their financial risk created stronger incentives for cost control. This group served as a test case for how physician compensation might be structured if practices faced these incentives.

We specified 2 regression models in which the percentage of primary care physician compensation for salary and for quality were estimated as a function of ACO participation and risk for primary care costs while controlling for other practice characteristics (practice size, multispecialty vs primary care, physician owned vs hospital owned, and the practices' percentage of patients with limited English proficiency).

Our research was approved by institutional review board committees at the University of California Berkeley, Berkeley, California, and Weill Cornell Medical College, New York, New York.

\section{RESULTS}

Compensation for primary care physicians varied considerably across study practices (Figure 1). Primary care physicians in ACO practices on average received $49.0 \%$ of their compensation from salary, $46.1 \%$ from productivity, 3.4\% from quality, and 1.5\% from other factors (Figure 2). This pattern of compensation was similar to practices that are not in ACOs and did not have substantial risk for primary care costs. In contrast, primary care physicians that were not in ACOs practices but had substantial risk for primary care costs received $66.6 \%$ of their compensation from salary, $32.2 \%$ from productivity, $0.8 \%$ from quality, and $0.4 \%$ from other factors.

In multivariate analysis, participating in an ACO was not significantly associated with primary care phy- 
Figure 1. Composition of primary care physician compensation across study sample.

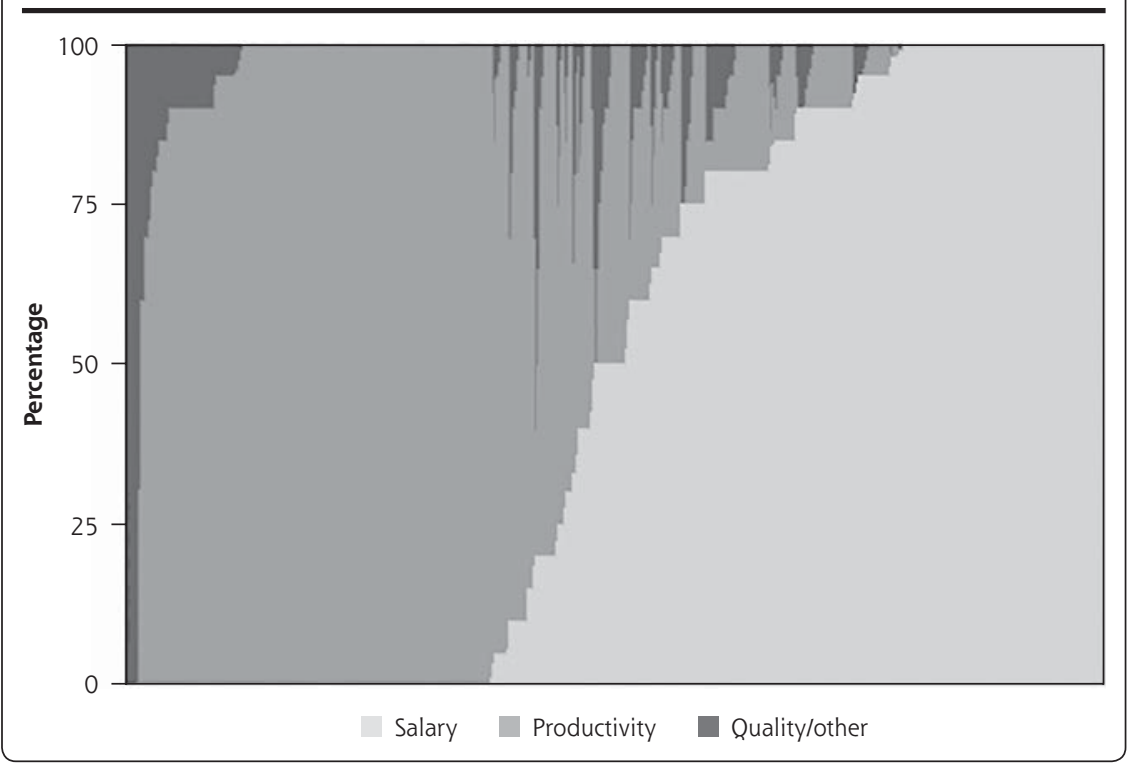

ACO but had substantial risk for primary care costs found the same pattern of results (Supplemental Appendix, available at http://www.annfammed.org/content/13/4/321/ suppl/DC1/).

\section{DISCUSSION}

Variation in primary care compensation across practices likely reflects different incentives faced by practices and a lack of consensus about the most appropriate ways to pay primary care physicians. What our findings mean for ACOs is subject to different interpretation. Current compensation policies for primary care physicians in ACOs may

sicians' compensation from salary (Table 1). Substantial risk for primary care costs was associated, however, with a 35.5 percentage point increase $(P<.05)$ in physicians' compensation from salary. Participating in an $\mathrm{ACO}$ was associated with a 2.2 percentage point increase $(P<.01)$ in primary care physicians' compensation for quality. Sensitivity analysis that excluded the $2.3 \%$ of practices that were not participating in an be the right mix of salary, productivity, and quality for both ACOs and for national policy. That primary care compensation for practices in ACOs looks more similar to a cross-section of US practices than to practices with substantial risk for primary care costs may be inconsequential. ACOs have other mechanisms, apart from physician compensation, to manage costs, such as more effective use of electronic health records, use

\section{Table 1. Association Between Practice Participation in ACOs, Risk for Primary Care Costs, and Primary Care Physician Compensation ( $\mathrm{N}=628$ )}

\begin{tabular}{|c|c|c|}
\hline Independent Variable & $\begin{array}{c}\text { Percentage Point } \\
\text { Change in Physician } \\
\text { Compensation for Salary } \\
(95 \% \mathrm{Cl})\end{array}$ & $\begin{array}{c}\text { Percentage Point } \\
\text { Change in Physician } \\
\text { Compensation for Quality } \\
(95 \% \mathrm{Cl})\end{array}$ \\
\hline Does not participate in a CMS ACO program (reference) & $\ldots$ & $\ldots$ \\
\hline Participates in a CMS ACO program & $-3.5(-12.0$ to 4.9$)$ & $2.2(1.4 \text { to } 2.9)^{a}$ \\
\hline Does not take substantial risk for primary care costs (reference) ${ }^{b}$ & $\ldots$ & $\ldots$ \\
\hline Takes substantial risk for primary care costs ${ }^{b}$ & $35.5(8.5 \text { to } 62.5)^{c}$ & $-1.0(-3.6$ to 1.5$)$ \\
\hline Number of physicians in practice & $-0.02(-0.09$ to 0.04$)$ & $-0.001(-0.008$ to 0.006$)$ \\
\hline Only primary care physicians (reference) & $\ldots$ & $\ldots$ \\
\hline Multispecialty practice & $-8.3(-27.1$ to 10.6$)$ & $-0.1(-3.9$ to 3.7$)$ \\
\hline Practice owned by hospital or health system (reference) & $\ldots$ & $\ldots$ \\
\hline Practice owned by physicians & $-8.3(-15.4 \text { to }-1.1)^{c}$ & $-8.0(-11.5 \text { to }-4.6)^{\mathrm{a}}$ \\
\hline Practice owned by other group ${ }^{d}$ & $-13.0(-59.7$ to 33.8$)$ & $-6.9(-13.4 \text { to }-0.4)^{c}$ \\
\hline Percentage of patients whose primary language is not English & $0.5(0.4 \text { to } 0.6)^{\mathrm{a}}$ & $-0.04(-0.09$ to 0.01$)$ \\
\hline
\end{tabular}




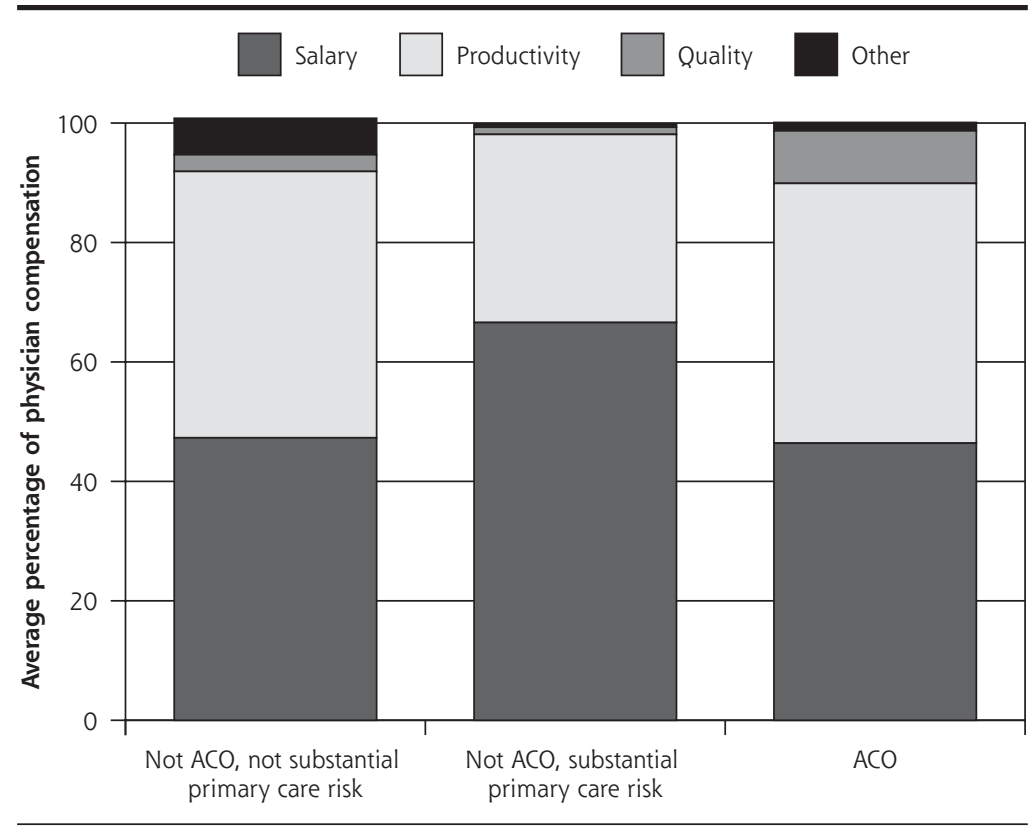

$\mathrm{ACO}=$ accountable care organization

Note: Substantial risk denotes that a practice bears at least some financial risk for primary care costs for all of its health maintenance organization or point-of-service patients.

\section{Figure 2. Primary care physician compensation across financial risk and ACO participation.}

Key words: accountable care organizations; physicians; insurance, health, reimbursement; value-based purchasing

Submitted October 31, 2014; submitted, revised, March 9, 2015; accepted April 8, 2015.

Funding support: This research was funded by the Robert Wood Johnson Foundation (grant \#68847).

Disclaimer: The funder had no role in the design or conduct of this study.

Acknowledgments: We would like to acknowledge Frances Wu for assistance with the data analysis for this article.

\section{Supplementary materials:}

Available at http://www.AnnFamMed.org/ content/13/4/321/suppl/DC1/

\section{References}

1. Shortell SM, McClellan SR, Ramsay PP, Casalino LP, Ryan AM, Copeland KR. Physician practice participation in accountable care organizations: the emergence of the unicorn. Health Serv Res. 2014;49(5):1519-1536.

2. Robinson JC, Shortell SM, Li R, Casalino LP Rundall T. The alignment and blending of payment incentives within physician organizations. Health Serv Res. 2004;39(5):1589-1606.

of nurse care managers for coordinating care for highrisk patients, and production of internal reports-seen by all physicians-on physicians' performance. ${ }^{7,8}$ The higher compensation for quality in ACOs may signal that the incentives of physicians and practices in ACOs are better aligned to achieve the quality measures that are rewarded in the Centers for Medicare and Medicaid Services programs. ${ }^{9}$

In contrast, the incentives for ACOs may not be sufficiently strong to encourage practices to rapidly and substantively change their physician compensation policies to create incentives for better patient experience, improved population health, and lower per capita costs. ${ }^{10}$ If physicians in ACOs and physicians outside ACOs are paid similarly, will they practice differently? The ACO experiment is new, and it may take some time and experimentation for practices to shift toward the most effective compensation policies for their physicians. ${ }^{11}$ Ongoing evaluations will assess whether the ACO programs are effective in achieving the triple aim. ${ }^{12}$ Nonetheless, if incentives are not aligned between practices and physicians, the ACO programs may have limited effects on costs and quality in the short-term.

To read or post commentaries in response to this article, see it online at http://www.annfammed.org/content/13/4/321.
3. Robinson JC. Theory and practice in the design of physician payment incentives. Milbank Q. 2001;79(2):149-177, III.

4. Lee TH, Bothe A, Steele GD. How Geisinger structures its physicians' compensation to support improvements in quality, efficiency, and volume. Health Aff (Millwood). 2012;31(9):2068-2073.

5. Robinson JC, Shortell SM, Rittenhouse DR, Fernandes-Taylor S, Gillies RR, Casalino LP. Quality-based payment for medical groups and individual physicians. Inquiry. 2009;46(2):172-181.

6. Landon BE, O'Malley AJ, McKellar MR, Reschovsky JD, Hadley J. Physician compensation strategies and quality of care for Medicare beneficiaries. Am J Manag Care. 2014;20(10):804-811.

7. Rittenhouse DR, Shortell SM, Gillies RR, et al. Improving chronic illness care: findings from a national study of care management processes in large physician practices. Med Care Res Rev. 2010;67(3): 301-320.

8. Singer S, Shortell SM. Implementing accountable care organizations: ten potential mistakes and how to learn from them. JAMA. 2011;306(7):758-759.

9. Greene J, Hibbard JH, Overton V. A case study of a team-based, quality-focused compensation model for primary care providers. Med Care Res Rev. 2014;71(3):207-223.

10. Berwick DM, Nolan TW, Whittington J. The triple aim: care, health and cost. Health Aff (Millwood). 2008;27(3):759-769.

11. Colla CH, Lewis VA, Shortell SM, Fisher ES. First national survey of ACOs finds that physicians are playing strong leadership and ownership roles. Health Aff (Millwood). 2014;33(6):964-971.

12. McWilliams JM, Landon BE, Chernew ME, Zaslavsky AM. Changes in patients' experiences in Medicare Accountable Care Organizations. N Engl J Med. 2014;371(18):1715-1724. 